\title{
SISTEM PENDUKUNG KEPUTUSAN PENENTUAN PENERIMA PROGRAM BANTUAN RASTRA DI KECAMATAN MAULAFA MENGGUNAKAN METODE WEIGHTED PRODUCT
}

\author{
Meliana O. Meo' ${ }^{1}$, Donzilio Antonio Meko \\ ${ }^{1}$ Program Studi Teknik Informatika STIKOM Uyelindo Kupang \\ ${ }^{2}$ Program Studi Teknik InformatikaSTIMIK Kupang \\ Email: ${ }^{1}$ meliana.oktavia.g@gmail.com1, ${ }^{2}$ donzi.antonio.g@ gmail.com²
}

\begin{abstract}
Abstrak - Salah satu persoalan mendasar yang di alami pemerintah Indonesia adalah masalah kemiskinan Oleh karena itu untuk mengatasi masalah tersebut salah satu cara yang dilakukan pemerintah Indonesia adalah dengan melaksanakan program subsidi beras sejahtera (Rastra). Pengambilan keputusan untuk menentukan kriteria penerima beras yang sudah terjadi biasanya tidak mengacu pada kriteria-kriteria keluarga sehingga sering terjadi kecurangan dan bantuan tidak tepat sasaran, berdasarkan hal tersebut maka diperlukan sebuah sistem untuk menentukan siapa yang layak untuk menerima bantuan tersebut. Tujuan dari penelitian ini adalah untuk menciptakan sebuah sistem pendukung keputusan untuk menentukan penerima Rastra di Kecamatan Maulafa Kota Kupang. Subjek penelitian ini adalah penentuan penerimaan beras miskin dengan menerapkan metode Weighted Product (WP). Teknik pengumpulan data yang digunakan dalam penelitian ini adalah observasi, literatur review, dan wawancara. Hasil dari penelitian ini adalah penerapan metode Weighted Product untuk menentukan penerima bantuan Rastra di Kecamatan Maulafa sehingga dapat digunakan, membantu mempercepat penentuan penerima Rastra .
\end{abstract}

Kata Kunci Weighted Product, Sistem Pendukung Keputusan, Rastra.

\section{PENDAHULUAN}

Salah satu persoalan mendasar yang di alami pemerintah Indonesia adalah masalah kemiskinan dan kesejahteraan masyarakat. Oleh karena itu untuk mengatasi masalah tersebut salah satu cara yang dilakukan pemerintah Indonesia adalah dengan melaksanakan program subsidi beras sejahtera (Rastra).

Rastra merupakan sebuah program dari pemerintah untuk mengurangi beban penyaluran dari rumah tangga miskin sebagai bentuk dukungan dalam meningkatkan ketahanan pangan dengan memberikan perlindungan sosial beras murah dengan jumlah maksimal $15 \mathrm{~kg} / \mathrm{rumah}$ tangga miskin/bulan dengan masing-masing seharga Rp. 1.600,00 per kg (netto) di titik distribusi [1].

Kecamatan Maulafa Kota Kupang, merupakan salah satu kecamatan yang mendapatkan program bantuan beras sejahtera. Mekanisme pembagian bantuan Rastra di kecamatan Maulafa dilakukan secara bertahap yaitu tiga bulan sekali, dimana setiap kepala keluarga (KK) mendapatkan $15 \mathrm{Kg}$ Rastra.

Penyaluran Rastra dilakukan lewat tiap-tiap RT. Penentuan layak tidaknya keluarga penerima bantuan Rastra yang dilakukan oleh pihak kecamatan Maulafa. Pengambilan keputusan untuk menentukan kriteria penerima beras yang sudah terjadi biasanya tidak mengacu pada kriteriakriteria keluarga sehingga sering terjadi kecurangan dan bantuan tidak tepat sasaran, berdasarkan hal tersebut maka diperlukan metode khusus untuk mencegah kesalahan dalam penentuan penerima Rastra.

Metode Weighted Product (WP) merupakan sebuah metode di dalam penentuan sebuah keputusan dengan cara perkalian untuk menghubungkan rating atribut, dimana rating setiap atribut harus dipangkatkan dulu dengan bobot atribut yang bersangkutan. Proses tersebut sama halnya dengan proses normalisasi [2]

Tujuan penelitian ini adalah membuat sebuah sistem aplikasi yang dapat digunakan oleh kecamatan Maulafa untuk mendukung keputusan seleksi penerimaan bantuan Rastra sesuai kriteria yang ditentukan dengan mengunakan metode weighted product.

\section{LANDASAN TEORI}

\subsection{Sistem Pendukung Keputusan}

Sistem pendukung keputusan merupakan sistem informasi interaktif yang menyediakan informasi, pemodelan dan manipulasi data. Sistem ini digunakan untuk membantu pengambil keputusan dalam situasi yang semi terstruktur dan situasi yang tidak terstruktur, dimana tidak seorang pun tahu secara pasti bagaimana keputusan seharusnya dibuat [3]

Sistem pendukung keputusan (SPK) dibangun untuk mendukung solusi atas suatu masalah untuk suatu peluang. Aplikasi sistem pendukung keputusan digunakan dalam pengambilan keputusan. Aplikasi SPK 
menggunakan CBIS (Computer Based Information System) yang fleksibel, interaktif dan dapat diadaptasi, yang dikembangkan untuk mendukung solusi atas masalah manajemen spesifik yang tidak terstruktur [2]

\subsection{Beras Sejahtera (RASTRA)}

Beras Sejahtera (RASTRA) merupakan salah satu program subsidi atau bantuan beras bagi masyarakat berpendapatan rendah yang disalurkan setiap bulan dengan alokasi sebesar $15 \mathrm{~kg}$ untuk setiap rumah tangga sasaran penerima manfaat (RTS-PM) dengan harga tebus sebesar Rp. $1.600 / \mathrm{kg}$ [1]. RASTRA diberikan dengan tujuan untuk mengurangi beban pengeluaran dan meningkatkan akses masyarakat miskin dan rentan melalui pemenuhan kebutuhan pangan pokok yang menjadi hak dasarnya.

\subsection{Metode Weighted Product (WP)}

Metode Weighted Product (WP) adalah salah satu metode penyelesaian pada sistem pendukung keputusan. Metode ini mengevaluasi beberapa alternatif terhadap sekumpulan atribut atau kriteria, dimana setiap atribut saling tidak bergantung satu dengan yang lainnya. Metode weighted product menggunakan teknik perkalian untuk menghubungkan rating atribut, dimana rating tiap atribut harus dipangkatkan terlebih dahulu dengan bobot atribut yang bersangkutan [4]. Proses tersebut sama halnya dengan proses normalisasi. Preferensi untuk alternatif $\mathrm{Ai}$ diberikan sebagai berikut [2]

$$
\begin{aligned}
& W_{j}=\frac{w_{j}}{\sum w_{j}} \\
& S_{i}=\Pi_{j=1}^{n} X_{i j}{ }^{w j}
\end{aligned}
$$

Keterangan :

$\Pi=$ produk atau jumlah kali

$\mathrm{S}=$ preferensi alternatif dianalogikan dengan vektor S

$\mathrm{X}=$ nilai kriteria

$\mathrm{W}=$ bobot atribut

$\mathrm{i}=$ alternative $($ dimana $\mathrm{I}=1,2, \ldots, \mathrm{n})$

$\mathrm{j}=$ kriteria

$\mathrm{n}$ = banyaknya kriteria adalah:

Preferensi relatif dari setiap alternatif,

$$
V_{i}=\frac{\Pi_{j=1}^{n} x_{i j}{ }^{w j}}{\Pi_{j=1}^{n}\left(x_{j *}\right)^{w j}}
$$

Keterangan:

$V_{i}=$ hasil preferensi alternatif ke-i

$X_{i j}=$ nilai kriteria

$W_{j}=$ bobot kriteria

$\mathrm{i}=$ alternatif

$j=$ kriteria $n$ = banyaknya kriteria

* = banyaknya kriteria yang telah dinilai pada vektor $\mathrm{S}$

Metode Weighted Product adalah tahapan metode penyelesaian dari masalah Multiple Attribute Decision Making (MADM). Metode Weighted Product mengevaluasi m alternatif Ai (i $=1,2 \ldots, \mathrm{m})$ terhadap sekumpulan atribut atau kriteria $\mathrm{Cj}(\mathrm{j}=1,2, \ldots, n)$, dimana setiap atribut saling tidak bergantung satu dengan yang lainnya. Matriks keputusan setiap alternatif terhadap setiap atribut atau kriteria, $\mathrm{X}$, diberikan sebagai berikut:

$$
x=\left[\begin{array}{ccc}
x_{11} & \ldots & x_{1 n} \\
\vdots & \ddots & \vdots \\
x_{m 1} & \ldots & x_{m n}
\end{array}\right]
$$

Dimana $x_{i j}$ merupakan rating kinerja alternatif ke-i terhadap atribut ke-j. Pada Tabel 1 menunjukan matrix keputusan setiap alternatif terhadap setiap atribut dalam penulisan berbentuk tabel yang berisi rating kinerja.

Tabel 1. Rating Kinerja

\begin{tabular}{|l|l|l|c|l|}
\hline \multirow{2}{*}{ Alternatif } & \multicolumn{4}{|c|}{ Kriteria } \\
\cline { 2 - 5 } & \multicolumn{1}{|c|}{$\mathrm{C1}$} & \multicolumn{1}{|c|}{$\mathrm{C2}$} & $\ldots$ & \multicolumn{1}{c|}{$\mathrm{Cn}$} \\
\hline $\mathrm{Al}$ & $\mathrm{X} 1 \mathrm{X}$ & $\mathrm{X} 12$ & $\ldots$ & $\mathrm{X} \ln$ \\
\hline $\mathrm{A} 2$ & $\mathrm{X} 12$ & $\mathrm{X} 22$ & $\ldots$ & $\mathrm{X} 2 \mathrm{n}$ \\
\hline$\ldots$ & $\ldots$ & $\ldots$ & $\ldots$ & $\ldots$ \\
\hline $\mathrm{Am}$ & $\mathrm{X} 1 \mathrm{~m}$ & $\mathrm{X} 2 \mathrm{~m}$ & $\ldots$ & $\mathrm{Xnm}$ \\
\hline
\end{tabular}

Nilai bobot yang menunjukan tingkat kepentingan setiap atribut, dimaksudkan sebagai $\mathrm{W}=\{\mathrm{w} 1, \mathrm{w} 2, \ldots, \mathrm{wn}\}$.

Secara singkat langkah-langkah penyelesaian masalah dengan menggunakan metode Weighted Product adalah sebagai berikut [2]

1. Menentukan kriteria-kriteria yang akan dijadikan acuan dalam pengambilan keputusan.

2. Menentukan rating kecocokan setiap alternatif pada setiap kriteria.

3. Memperbaiki nilai bobot terlebih dahulu dengan cara membagi bobot dengan rata-rata bobot $(\mathrm{Wj}=1)$.

4. Nilai seluruh atribut kriteria dipangkatkan dengan bobot yang telah diperbaiki. Bagi sebuah alternatif keuntungan bernilai bobot pangkat positif sedangkan alternatif biaya bernilai bobot pangkat negatif.

5. Seluruh nilai atribut kriteria dikalikan berdasarkan jumlah kriteria yang dimiliki setiap alternatif.

6. Hasil perkalian dijumlahkan untuk menghasilkan nilai pada setiap alternatif. 
7. Mencari nilai hasil dengan melakukan pembagian dengan rata-rata dari nilai hasil setiap perkalian.

8. Ditemukan urutan hasil alternatif terbaik yang akan menjadi keputusan.

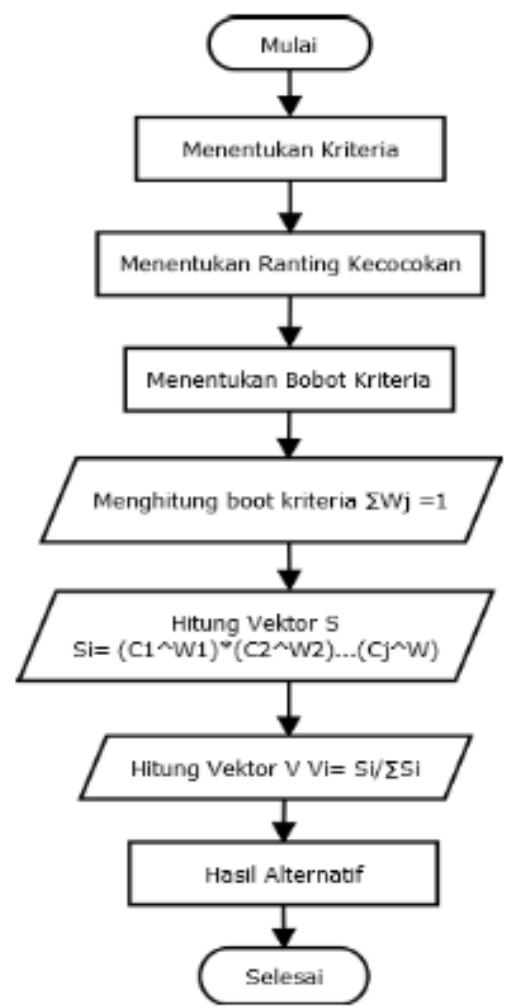

Gambar 1. Flowchart Metode Weighted Product

\section{METODE PENELITIAN}

Penelitian dilakukan di Kecamatan Maulafa Kota Kupang. Dalam penelitian ini data yang digunakan adalah data penerima bantuan Rastra tahun 2018. Adapun rencana pengumpulan sumber data dengan cara sebagai berikut :

1. Sumber Data Primer
a. Interview
b. Observasi

2. Sumber Data Sekunder
a. Studi Dokumentasi
b. Studi Kepustakaan

\subsection{Analisa Sistem}

Dalam tahapan analisa sistem ini, peneliti mengumpulkan data yang dibutuhkan untuk menentukan penerima manfaat bantuan. Sejauh ini ada 6 kriteria yang digunakan dalam menentukan siapa yang berhak mendapat bantuan. Rastra yaitu Jenis pekerjaan, jumlah penghasilan, jumlah tanggungan, kondisi rumah, kepemilikan rumah, dan umur

\subsection{Prosedur Penelitian}

Prosedur penelitian merupakan tahapantahapan yang dilalui oleh peneliti dari permulaan pengumpulan data sampai kesimpulan, yang membentuk sebuah alur yang sistematis. Metodologi penelitian ini digunakan sebagai pedoman peneliti dalam pelaksanaan penelitian sehingga hasil yang dicapai dan tujuan yang di inginkan dapat terwujud. Berikut ini rancangan flowchart prosedur penelitian.

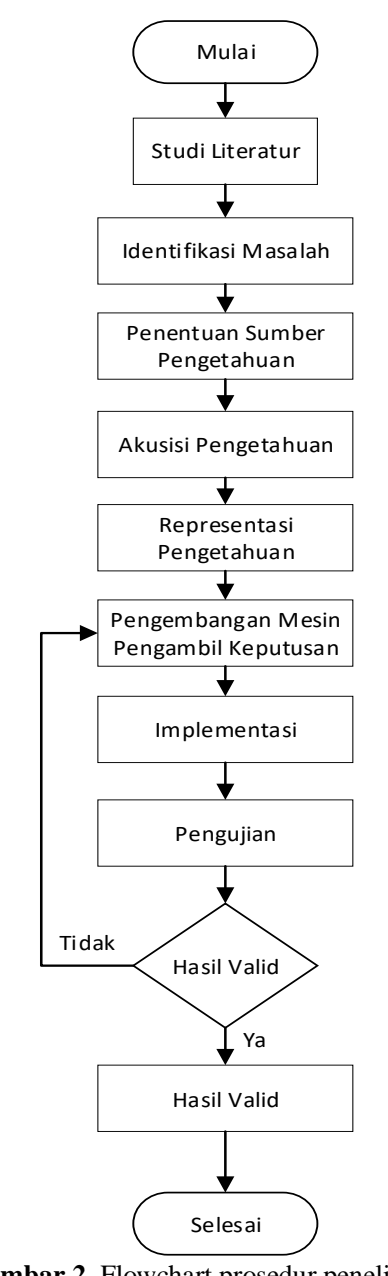

Gambar 2. Flowchart prosedur penelitian

\subsection{Analisis Kasus}

Tahapan-tahapan dalam penerapan metode Weighted Product adalah sebagai berikut :

1. Penentuan alternatif

Alternatif yang digunakan dalam kasus ini adalah data calon penerima bantuan Rastra. Berikut nama-nama alternatif yang digunakan sebagai sampel: 
Meo dan Meko, Sistem Pendukung Keputusan Penentuan Penerima Program Bantuan Rastra di Kecamatan Maulafa Menggunakan Metode Weighted Product

Tabel 2. Nama-nama Alternatif

\begin{tabular}{c|c|} 
Kode Alternatif & Nama Alternatif \\
\hline A1 & Marsel Nahak \\
\hline A2 & Agustinus Kase \\
\hline A3 & Terezinha Fallo \\
\hline A4 & Agus Tallo \\
\hline A5 & Yunus Missa \\
\hline A6 & Anton Seran \\
\hline
\end{tabular}

2. Penentuan Kriteria

Penentuan Kriteria diperoleh dari hasil penilaian. Terdapat enam kriteria yang digunakan untuk memberikan penilaian terhadap Calon Penerima bantuan Rastra seperti pada tabel 3 berikut:

Tabel 3. Kriteria dan Bobot Nilai

\begin{tabular}{|c|c|c|}
\hline $\begin{array}{l}\text { Nama } \\
\text { Kriteria }\end{array}$ & Range Nilai & $\begin{array}{l}\text { Bobot } \\
\text { Nilai }\end{array}$ \\
\hline \multirow{6}{*}{$\begin{array}{l}\text { Jenis } \\
\text { Pekerjaan }\end{array}$} & $\begin{array}{c}\text { Tidak } \\
\text { bekerja/pengangguran }\end{array}$ & 5 \\
\hline & Buruh & 4 \\
\hline & Swasta & 3 \\
\hline & Wiraswasta & 2 \\
\hline & $\begin{array}{c}\text { PNS/Pegawai } \\
\text { Lainnya }\end{array}$ & 1 \\
\hline & Tidak Tetap & 5 \\
\hline \multirow{4}{*}{$\begin{array}{c}\text { Jumlah } \\
\text { Penghasilan }\end{array}$} & $<500$ perbulan & 4 \\
\hline & $500 \mathrm{~s} / \mathrm{d} 1$ juta & 3 \\
\hline & $>1$ juta & 2 \\
\hline & $>2$ juta & 1 \\
\hline \multirow{5}{*}{$\begin{array}{c}\text { Jumlah } \\
\text { Tanggungan }\end{array}$} & 5 anak atau lebih & 5 \\
\hline & 4 & 4 \\
\hline & 3 anak & 3 \\
\hline & 2 anak & 2 \\
\hline & 1 atau tidak punya & 1 \\
\hline \multirow{5}{*}{$\begin{array}{l}\text { Kondisi } \\
\text { Rumah }\end{array}$} & Dinding & 5 \\
\hline & Bambu & 4 \\
\hline & Bata & 3 \\
\hline & Tembok & 2 \\
\hline & Beton & 1 \\
\hline \multirow{3}{*}{ Kepemilikan } & Hak Milik & 5 \\
\hline & Sewa Tanah & 4 \\
\hline & Kos & 3 \\
\hline \multirow{5}{*}{ Umur } & 60 Keatas & 5 \\
\hline & $50-60$ & 4 \\
\hline & $40-50$ & 3 \\
\hline & $30-40$ & 2 \\
\hline & 30 kebawah & 1 \\
\hline
\end{tabular}

3. Penentuan Bobot Preferensi dan Normalisasi Bobot

Penentuan bobot preferensi dinilai dari kriteria yang memiliki pengaruh besar terhadap proses penilaian seleksi dari kriteria lainnya.

\begin{tabular}{c|c|}
\multicolumn{2}{c|}{ Tabel 4. Bobot Preferensi } \\
Nama Kriteria & $\begin{array}{c}\text { Bobot } \\
\text { Nilai }\end{array}$ \\
\hline Jenis Pekerjaan & 9 \\
\hline Jumlah Penghasilan & 15 \\
\hline Jumlah Tanggungan & 9 \\
\hline Kondisi Rumah & 9 \\
\hline Kepemilikan Rumah & 9 \\
\hline Umur & 9 \\
\hline \multicolumn{2}{|c}{}
\end{tabular}

Langkah berikutnya melakukan perbaikan bobot atau normalisasi bobot,dimana $\sum w_{j}=1$

$$
\begin{gathered}
W_{j}=\frac{w_{j}}{\sum w_{j}} \\
\mathrm{~W}_{1}=\frac{9}{15+9+9+9+9+9}=\frac{9}{60}=0.15 \\
\mathrm{~W}_{2}=\frac{15}{15+9+9+9+9+9}=\frac{15}{60}=025 \\
\mathrm{~W}_{3}=\frac{9}{15+9+9+9+9+9}=\frac{9}{60}=0.15 \\
\mathrm{~W}_{4}=\frac{9}{15+9+9+9+9+9}=\frac{9}{60}=0.15 \\
\mathrm{~W}_{5}=\frac{9}{15+9+9+9+9+9}=\frac{9}{60}=0.15 \\
\mathrm{~W}_{6}=\frac{9}{15+9+9+9+9+9}=\frac{9}{60}=0.15
\end{gathered}
$$

4. Menghitung Vektor S

Setelah melakukan normalisasi bobot maka akan dilakukan perhitungan Vektor $\mathrm{S}$ dengan rumus :

$$
S_{i}=\Pi_{j=1}^{n} X_{i j}{ }^{w j}
$$

$\mathrm{S} 1=\left(4^{\wedge} 0.15\right)^{*}\left(2^{\wedge}-0.25\right)^{*}\left(3^{\wedge} 0.15\right)^{*}\left(2^{\wedge} 0.15\right)^{*}\left(5^{\wedge} 0.15\right)^{*}\left(3^{\wedge} 0.15\right)=2.0332$ $\mathrm{S} 2=\left(5^{\wedge} 0.15\right)^{*}\left(2^{\wedge}-0.25\right)^{*}\left(4^{\wedge} 0.15\right)^{*}\left(5^{\wedge} 0.15\right)^{*}\left(4^{\wedge} 0.15\right)^{*}\left(5^{\wedge} 0.15\right)=2.6296$ $\mathrm{S} 3=\left(5^{\wedge} 0.15\right)^{*}\left(5^{\wedge}-0.25\right)^{*}\left(4^{\wedge} 0.15\right)^{*}\left(2^{\wedge} 0.15\right)^{*}\left(5^{\wedge} 0.15\right)^{*}\left(5^{\wedge} 0.15\right)=1.8848$ $\mathrm{S} 4=\left(4^{\wedge} 0.15\right)^{*}\left(3^{\wedge}-0.25\right)^{*}\left(3^{\wedge} 0.15\right)^{*}\left(2^{\wedge} 0.15\right)^{*}\left(5^{\wedge} 0.15\right)^{*}\left(4^{\wedge} 0.15\right)=1.9183$ $\mathrm{S} 5=\left(3^{\wedge} 0.15\right)^{*}\left(2^{\wedge}-0.25\right)^{*}\left(5^{\wedge} 0.15\right)^{*}\left(2^{\wedge} 0.15\right)^{*}\left(5^{\wedge} 0.15\right)^{*}\left(4^{\wedge} 0.15\right)=2.1952$ $\mathrm{S} 6=\left(2^{\wedge} 0.15\right)^{*}\left(2^{\wedge}-0.25\right)^{*}\left(4^{\wedge} 0.15\right)^{*}\left(5^{\wedge} 0.15\right)^{*}\left(5^{\wedge} 0.15\right)^{*}\left(5^{\wedge} 0.15\right)=2.37$

\section{Menentukan Vektor V}

Menentukan Nilai vector yang akan digunakan Menghitung Preferensi (Vi) untuk perengkingan dengan rumus : 


$$
\begin{gathered}
V i=\frac{\prod_{j}^{n}=1 X_{i j}^{w j}}{\prod_{j}^{n}=1\left(X_{j^{*}}\right)^{w j}} \\
\mathrm{~V} 1=\frac{2.0332}{2.0332+2.6296+1.8848+1.9183+2.1952+2.37}=0.156 \\
\mathrm{~V} 2=\frac{2.6296}{2.0332+2.6296+1.8848+1.9183+2.1952+2.37}=0.2018 \\
\mathrm{~V} 3=\frac{1.8848}{2.0332+2.6296+1.8848+1.9183+2.1952+2.37}=0.1446 \\
\mathrm{~V} 4=\frac{1.9183}{2.0332+2.6296+1.8848+1.9183+2.1952+2.37}=0.1472 \\
\mathrm{~V} 5=\frac{2.1952}{2.0332+2.6296+1.8848+1.9183+2.1952+2.37}=0.1685 \\
\mathrm{~V} 6=\frac{L .3 \prime}{2.0332+2.6296+1.8848+1.9183+2.1952+2.37}=0.1819
\end{gathered}
$$

Langkah terakhir adalah menentukan nilai rata-rata sehingga dapat menentukan alternative yang layak menerima bantuan, dengan rumus Average :

$$
\text { Nilai rata }- \text { rata }=\frac{\text { jumlah nilai }}{\text { banyaknya data }}
$$

Nilai rata - rata

$$
\begin{aligned}
& =\frac{0.156+0.2018+0.1446+0.1472+0.1685+0.1819}{6} \\
& =0.167
\end{aligned}
$$

Tabel 5. Tabel Proses Perangkingan

\begin{tabular}{c|c|c|c|} 
Alternatif & Nama & Nilai & Status \\
& & & \\
\hline A1 & Marsel Nahak & 0.156 & Tidak Layak \\
\hline A2 & Agustinus Kase & 0.2018 & Layak \\
\hline A3 & Terezinha Fallo & 0.1446 & Tidak Layak \\
\hline A4 & Agus Tallo & 0.1472 & Tidak Layak \\
\hline A5 & Yunus Missa & 0.1685 & Layak \\
\hline A6 & Anton Seran & 0.1819 & Layak \\
\hline
\end{tabular}

Berdasarkan hasil perhitungan rata-rata alternatif yang layak mendapatkan bantuan adalah alternatif dengan nilai diatas 0.167 , maka alternatif A2, A5, dan A6 adalah alternatif yang terpilih menjadi alternatif terbaik. Dengan Kata lain calon penerima bantuan Rastra atas nama Agustinus Kase, Yunus Missa dan Anton Seran.

\section{HASIL PEMBAHASAN}

Implementasi dalam program ini menggunakan Microsoft Visual Studio 10. Berikut ini merupakan tampilan dari aplikasi yang dirancang.

a. Tampilan Form Data Alternatif

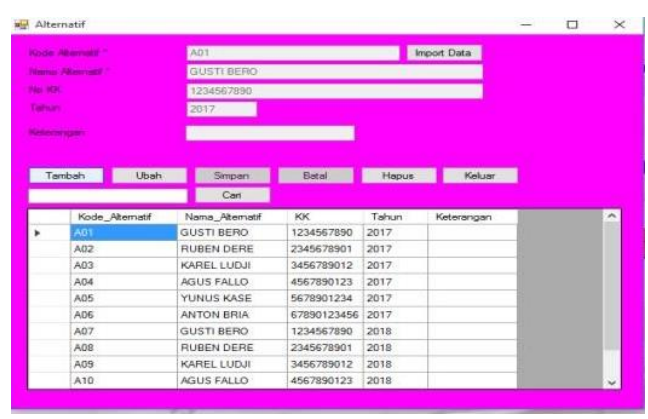

Gambar 3. Tampilan Form Data Alternatif

b. Tampilan Form Data Kriteria

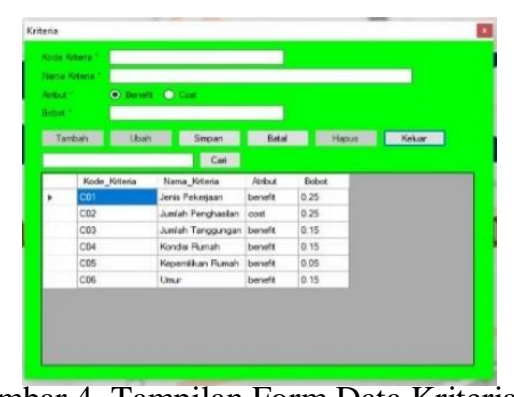

Gambar 4. Tampilan Form Data Kriteria

Tampilan Form Data Detail Kriteria

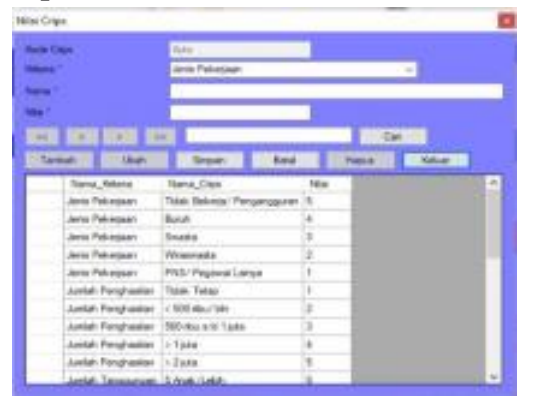

Gambar 5. Tampilan Form Data Detail Kriteria

d. Tampilan Form Data Perhitungan Nilai Bobot

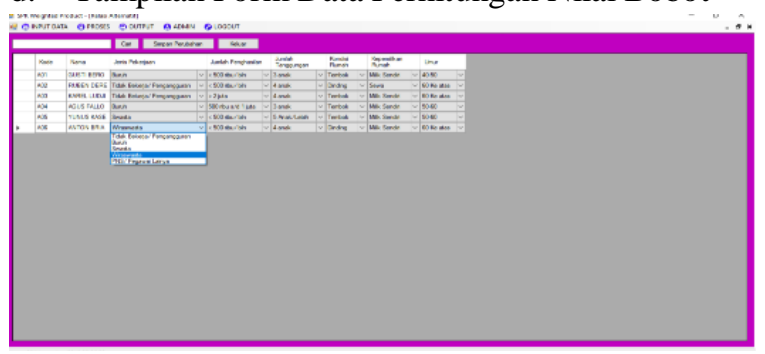

Gambar 6. Tampilan Form Data Perhitungan Nilai Bobot

e. Tampilan Hasil Perhitungan (Perangkingan) 
Meo dan Meko, Sistem Pendukung Keputusan Penentuan Penerima Program Bantuan Rastra di Kecamatan Maulafa Menggunakan Metode Weighted Product

\begin{tabular}{|c|c|c|c|c|}
\hline kode_altematif & aama_altematif & total & rank & status \\
\hline AOL & ROEECNOERE & 0.20 & 1 & Layak \\
\hline$A 06$ & ANTON BRIA & 0.18 & 2 & Layak \\
\hline A05 & YUNUS KASE & 0.17 & 3 & Tidak Layak \\
\hline A01 & GUSTI BERO & 0.16 & 4 & Tidak Layak \\
\hline $\mathrm{A} 04$ & AGUS FALLO & 0.15 & 5 & Tidak Layak \\
\hline A03 & KARELLUDJI & 0.14 & 6 & Tidak Layak \\
\hline
\end{tabular}

Gambar 7. Tampilan Form Data Hasil Perhitungan / Perangkingan

\section{KESIMPULAN}

1. Dengan adanya sistem pendukung keputusan ini diharapkan dapat membantu petugas Kecamatan Maulafa dalam memberikan rekomendasi keputusan penentuan penerimaan bantuan Rastra yang layak dengan cepat dan tepat bagi Kecamatan Maulafa.
2. Penerapan metode Weighted Product dalam sistem penentuan penerima bantuan rastra ini memberikan hasil yang sama dengan perhitungan manual, namun proses perhitungannya lebih singkat.

\section{REFERENSI}

[1] Kementrian Koordinator Pembangunan Manusia dan Kebudayaan, 2018, Pedoman Umum Bantuan Sosial Beras Sejahtera, Jakarta Pusat

[2] Nofriansyah, D. 2014, Konsep Data Mining vs Sistem Pendukung Keputusan, Yogyakarta(ID) : Deepublish.

[3] Kusrini, 2007, Strategi Perancangan dan Pengolahan Basis Data, Yogyakarta (ID): Andi.

[4] Kusumadewi, Sri. 2006. Fuzzy Multi-Attribute Decision Making (Fuzzy MADM). Yogyakarta(ID) : Graha Ilmu. 